ni serán parte de la política pública en materia de regulación de la fertilidad, aquellos métodos cuyo objetivo o efecto directo sea provocar un aborto.

Artículo 5․ Si al momento de solicitarse la prescripción médica de un método anticonceptivo de emergencia o de solicitarse su entrega en el sistema público o privado de salud fuese posible presumir la existencia de un delito sexual en la persona del solicitante o para quien se solicita, el facultativo o funcionario que corresponda deberá poner los antecedentes a disposición del Ministerio Público, sin perjuicio de lo dispuesto en el artículo $198 \mathrm{del}$ Código Procesal Penal.

Habiéndose cumplido con lo establecido en el № 1 del Artículo 93 de la Constitución Política de la República y por cuanto he tenido a bien aprobarlo y sancionarlo; por tanto promúlguese y llévese a efecto como Ley de la República.

Santiago, 18 de enero de 2010. MICHELLE BACHELET JERIA, Presidenta de la República. Álvaro Erazo Latorre, Ministro de Salud. Mónica Jiménez de la Jara, Ministra de Educación. José Antonio Viera-Gallo Quesney, Ministro Secretario General de la Presidencia. Carmen Andrade Lara, Ministra Directora Servicio Nacional de la Mujer.

Lo que transcribo para su conocimiento. Saluda atentamente a Ud., Jeanette Vega Morales, Subsecretaria de Salud Pública.

\title{
Crónica
}

\section{ELECCIÓN DEL DIRECTORIO DE LA SOCIEDAD CHILENA DE OBSTETRICIA Y GINECOLOGÍA: PERÍODO 2010-201 1}

En una ceremonia encabezada por el actual presidente de la Sociedad Chilena de Obstetricia y Ginecología, Dr. Eugenio Suárez, el martes 22 de diciembre de 2009 , se realizó la elección de presidente de la SOCHOG para el período 2010- 2011. El presidente electo fue el Dr. Luis Martínez, quien actualmente se desempeña como vice-presidente de esta entidad científica, y asumirá el cargo a partir de abril de 2010.

De acuerdo a los estatutos de la Sociedad Chilena de Obstetricia y Ginecología, el Comité de Búsqueda de esta entidad se reunió en octubre de 2009, para proponer el listado de postulantes para ejercer los diferentes cargos del directorio para el periodo 2010-2011.
La propuesta de postulantes fue entregada durante una asamblea realizada en el auditorio de la Clínica Alemana Santiago, la cual fue aceptada por todos los miembros presentes en la ocasión.

De esta manera, fueron elegidos por aclamación los siguientes médicos con sus respectivos cargos: Presidente: Dr. Luis Martínez M.

Vice-presidente: Dr. Hernán Muñoz S.

Tesorero: Dr. Omar Nazzal N.

Secretario general: Dr. Mauricio Cuello F.

Secretarios de Actas: Drs. Carlos Schnapp Sch. y José Antonio Arraztoa V.

Directores: Drs. Álvaro Insunza F., Eduardo Faúndez P. y Dr. Fernando Abarzúa C. 